\title{
Systematic hardness studies on lithium niobate crystals
}

\author{
K G SUBHADRA, K KISHAN RAO and D B SIRDESHMUKH* \\ Department of Physics, Kakatiya University, Warangal 506 009, India
}

MS received 17 August 1999; revised 24 January 2000

\begin{abstract}
In view of discrepancies in the available information on the hardness of lithium niobate, a systematic study of the hardness has been carried out. Measurements have been made on two pure lithium niobate crystals with different growth origins, and a Fe-doped sample. The problem of load variation of hardness is examined in detail. The true hardness of $\mathrm{LiNbO}_{3}$ is found to be $630 \pm 30 \mathrm{~kg} / \mathrm{mm}^{2}$. The Fe-doped crystal has a larger hardness of $750 \pm 50 \mathrm{~kg} / \mathrm{mm}^{2}$.
\end{abstract}

Keywords. Microhardness; lithium niobate.

\section{Introduction}

Lithium niobate $\left(\mathrm{LiNbO}_{3}\right)$ is one of the most prominent nonlinear optical materials. Because of this importance, there is considerable work on all its physical properties (Nikogosyan 1997). One of the important properties of any device material is its mechanical strength, represented by its hardness. Physically, hardness is the resistance offered by a solid to the movement of dislocations. Practically, hardness is the resistance offered by a material to localized plastic deformation caused by scratching or by indentation. The hardness estimated from the scratch test is on the Moh's scale. The indentation hardness is measured as the ratio of the applied load to the surface area of the indentation (details in $\$ 2$ ). Indentation hardness measurement can, in principle, be carried out at fairly high loads $(\sim 100 \mathrm{~kg})$. But for materials which have low hardness and which are available as small-sized samples, it is convenient to make measurements at low loads of $<200 \mathrm{~g}$. This low-load hardness is called microhardness. There are discrepancies in the available information on the microhardness of $\mathrm{LiNbO}_{3}$.

Chai (1995) lists a value of 5 on the Moh scale for the hardness of $\mathrm{LiNbO}_{3}$. Using a conversion formula given by Mott (1956), we get a value of $400 \mathrm{~kg} / \mathrm{mm}^{2}$ on the Vickers scale. Brown et al (1975) made Knoop hardness measurements on the (001) plane at a single load of $50 \mathrm{~g}$ and obtained an average value of $570 \mathrm{~kg} / \mathrm{mm}^{2}$. It may be mentioned that Knoop and Vickers hardness values generally agree to within 5\% (Mott 1956). Brown et al (1975) also observed that there was no measurable anisotropy in the hardness on the (001) plane. Recently, Dhanraj et al (1994) reported measurements of Vickers hardness on the (001) plane, using crystals grown by them, and obtained a value of about $780 \mathrm{~kg} / \mathrm{mm}^{2}$ at a load

*Author for correspondence of $50 \mathrm{~g}$ (same load as used by Brown et al 1975). Thus there is a scatter of values from $400-800 \mathrm{~kg} / \mathrm{mm}^{2}$ in the reported microhardness values.

The other discrepancy is related to the load dependence of hardness of $\mathrm{LiNbO}_{3}$ observed by Dhanraj et al (1994). In ideal circumstances, measured hardness values should be independent of the applied load. But in practice, a load-dependence is observed. Typically, the measured hardness has a high value at very low loads. As the load is increased, there is a steep fall in the hardness. At still higher loads, the rate of fall in hardness with load decreases and, finally, the hardness becomes load independent. The load vs hardness curve is smooth. The cause of such load-variation, and the method to obtain the true hardness will be discussed later. Suffice it to mention that such load dependence is due to a systematic factor which is equivalent to a load correction. This correction, may vary from sample to sample, but is not related to the deformation mechanism in the crystal. Such load dependence has been observed in a variety of materials like metals (Mott 1956), ionic crystals (Pratap and Hari Babu 1980; Thirmal Rao and Sirdeshmukh 1991; Sirdeshmukh et al 1995; Sangaiah and Kishan Rao 1993), and minerals (Thirmal Rao and Sirdeshmukh 1994). Dhanraj et al (1994) observed that the microhardness of $\mathrm{LiNbO}_{3}$ has a value of $700 \mathrm{~kg} / \mathrm{mm}^{2}$ at a low load of $20 \mathrm{~g}$. In the load range $20-30 \mathrm{~g}$, they observed a steep increase in hardness to nearly $900 \mathrm{~kg} / \mathrm{mm}^{2}$. At higher loads they observed a decrease in hardness with a value of 600 at $100 \mathrm{~kg} / \mathrm{mm}^{2}$. The increase in hardness in the $20-30 \mathrm{~g}$ load range was attributed to work-hardening and the decrease at higher loads to plastic flow. Thus, the load-dependence observed by Dhanraj et al (1994) is at variance with several earlier observations. Furthermore, the interpretation of the observed behaviour as due to two different deformation mechanisms in different load regions would have new implications on the indentation process in $\mathrm{LiNbO}_{3}$. 
In view of these two discrepancies with regard to the true hardness of $\mathrm{LiNbO}_{3}$ and the load dependence of hardness in $\mathrm{LiNbO}_{3}$, it was considered desirable to undertake a systematic study of the hardness of $\mathrm{LiNbO}_{3}$. In the present communication, we report a detailed study of the load-dependence of hardness on two crystals of $\mathrm{LiNbO}_{3}$ of different origins, one of the crystals being from the same batch as used by Dhanraj et al (1994). A crystal of $\mathrm{Fe}$-doped $\mathrm{LiNbO}_{3}$ has also been included in the study.

\section{Experimental}

Pure lithium niobate $\left(\mathrm{LiNbO}_{3}\right)$ crystals (labelled A) were grown at the Indian Institute of Science, Bangalore, by the Czochralski method. The details of crystal growth are given elsewhere (Dhanraj et al 1994). They were oriented, cut and polished to reveal the (001) plane. Crystals of pure $\mathrm{LiNbO}_{3}$ (labelled $\mathrm{B}_{1}$ ) and $\mathrm{LiNbO}_{3}$ doped with 0.02 wt $\% \mathrm{Fe}$ (labelled $\mathrm{B}_{2}$ ) were grown by the same method at the Solid State Physics Laboratory, Delhi, and had the same orientation as crystal A. The details of crystal growth are discussed by Thyagarajan (1989). While crystals A and $B_{1}$ were colourless, crystal $B_{2}$ had a yellowish tinge. These crystals are shown in figure 1. Hardness measurements were made on the (001) plane at several loads in the range 15-200 g using a Miniload Leitz-Wetzlar hardness tester fitted with a Vickers diamond pyramidal indentor. The microhardness was calculated from the relation

$$
H_{\mathrm{v}}=1854 \cdot 4 P / d^{2},
$$

where $H_{\mathrm{v}}$ is the microhardness in $\mathrm{kg} / \mathrm{mm}^{2}, P$ the load in $g$, and $d$ the length of the diagonal of the indentation measured in $\mu$. At each load several indentations were made and the mean of the diagonal length was used. Though hard, $\mathrm{LiNbO}_{3}$ crystals are brittle. As a result, cracks show up in indentations made at and above $100 \mathrm{~g}$.

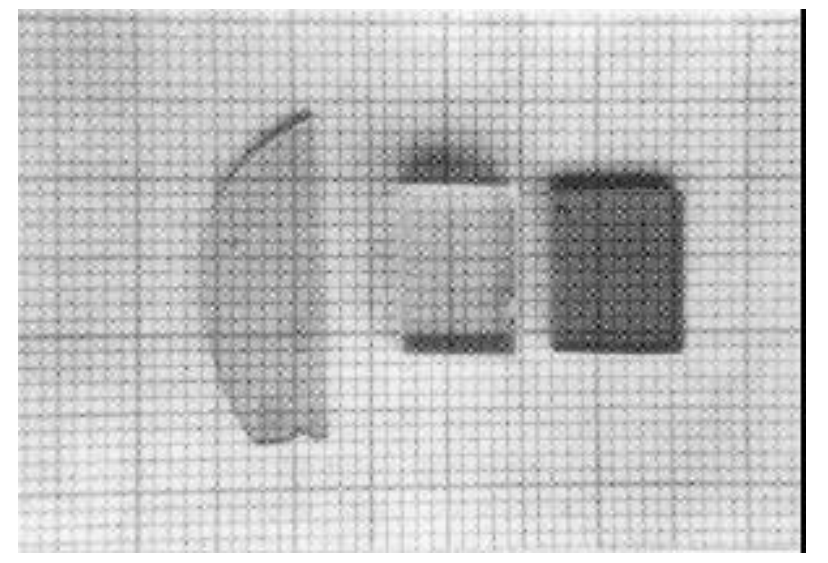

Figure 1. $\mathrm{LiNbO}_{3}$ crystals used for indentation (L-R: sample A, sample $B_{1}$ and sample $B_{2}$ ).
Such crack formations have been observed by Brown et al (1975) and Dhanraj et al (1994). Both linear cracks along the diagonal of the impression and curved cracks along the edges of the indentation were observed. With some care, measurements could be made up to $200 \mathrm{~g}$ on samples $A$ and $B_{1}$; whereas in sample $B_{2}$, the tendency to crack formation was more and measurements were limited to $100 \mathrm{~g}$. The measured hardness values at a given load are consistent among themselves within $2 \%$. In view of the report of Brown et al (1975) that there was no evidence of anisotropy of hardness on the (001) plane, no effort was made to maintain any definite orientation of the indentor on the (001) surface while making different indentations.

\section{Results and discussion}

The variation of hardness with load is shown in figure 2 . The observed load dependence is similar to the typical load dependence described in $\S 1$ : a high hardness value at low loads, a steep fall at higher loads, followed by a slower decrease with load, and, finally, a practically loadindependent behaviour. The load-independent behaviour is seen to occur beyond $100 \mathrm{~g}$ in samples $\mathrm{A}$ and $\mathrm{B}_{1}$; in sample $B_{2}$, this region is not reached as measurements were limited to $100 \mathrm{~g}$. It is to be noted that in all three samples, the load dependence is smooth.

Load variation of hardness of the type that has been observed can be interpreted in three different ways.

(i) Mott (1956) explains this type of load variation by assuming that the index of $d$ (the Meyer index) in (1) is not 2 but some value less than 2. Equation (1) is obtained by defining hardness as the ratio of the applied load to the surface area of the indentation. A value other than 2 for the index of $d$ strikes at this simple and meaningful definition of hardness.

(ii) Upit and Varchenya (1973) attribute this type of variation to the surface effect. The surface is harder than

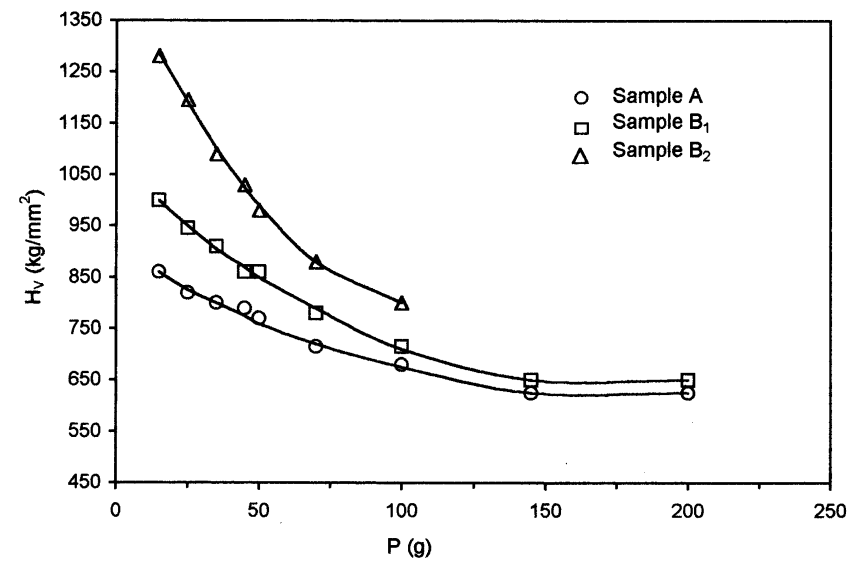

Figure 2. Plots of load $P$ against hardness $\left(H_{\mathrm{v}}\right)$. 


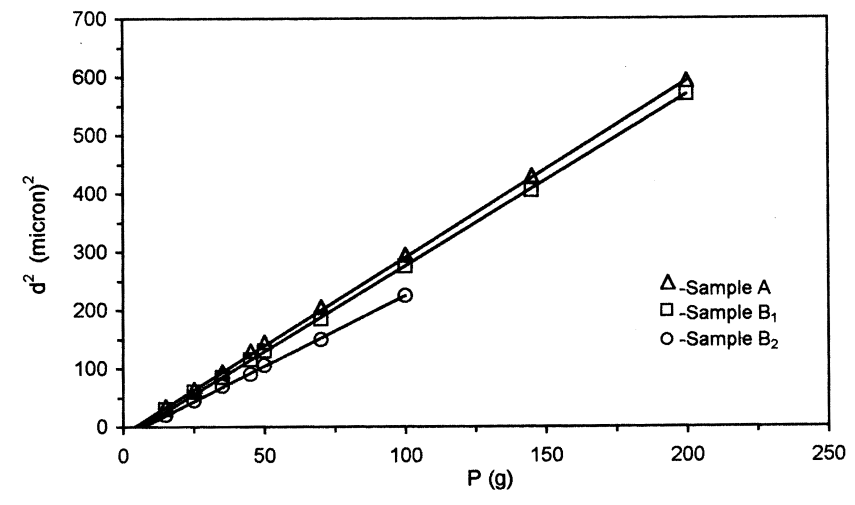

Figure 3. Plots of load $P$ against $d^{2}$.

the bulk, and hardness measured close to the surface (low loads) tends to have larger values. The true bulk hardness can be obtained by applying a correction which needs measurement of the depth of the indentation or by making hardness measurements at very high depths (high loads) where the surface effects become negligible and hardness becomes load independent.

(iii) Hayes and Kendall (1973) suggested that the observed load dependence may be due to the fact that the sample offers a resistance to deformation in the form of a Newtonian pressure. This is effectively equivalent to a negative load $W$ acting against the applied load $P$. Hayes and Kendall interpret $W$ as the minimum load to be applied to cause indentation as at any lesser load plastic deformation will not take place. A plot of $P$ vs $d^{2}$ will be a straight line whose intercept on the $P$-axis represents $W$. From this the true load-independent hardness $\left(H_{\mathrm{v}}^{0}\right)$ value can be evaluated by modifying (1) to:

$$
H_{\mathrm{v}}^{0}=1854 \cdot 4(P-W) / d^{2} \text {. }
$$

This last explanation of the observed load variation is simple and leads to meaningful estimates of the true bulk hardness. It reduces the cause of load variation to a systematic loading error. Furthermore, it is applicable to all crystals since it does not assume any particular deformation mechanism during indentation. Thirmal Rao and Sirdeshmukh (1991) have shown that the hardness value obtained from the flat region of $P$ vs $H_{\mathrm{v}}$ curve, and that obtained by the $W$-correction agree to within $2 \%$. Further, Thirmal Rao and Sirdeshmukh (1994) have also shown that this method can be applied even in cases where the $P$ vs $H_{\mathrm{v}}$ curve does not reach the flat region.

The present results are analysed following the method of Hayes and Kendall (1973). The $P-d^{2}$ plots for the three samples are shown in figure 3 . The values of the load correction $W$ obtained from these plots are given in table 1 . The values of the true hardness $\left(H_{\mathrm{v}}^{0}\right)$ are also given in the same table. It was mentioned in $\S 2$ that each hardness measurement yielded a value with an internal consistency
Table 1. Load correction $(W)$ and true hardness $\left(H_{\mathrm{v}}^{0}\right)$ of $\mathrm{LiNbO}_{3}$.

\begin{tabular}{lccc}
\hline Material & Sample code & $W(\mathrm{~g})$ & $\left(H_{\mathrm{v}}^{0}\right) \mathrm{kg} / \mathrm{mm}^{2}$ \\
\hline Pure $\mathrm{LiNbO}_{3}$ & $\mathrm{~A}$ & 4 & $630 \pm 30$ \\
Pure $\mathrm{LiNbO}_{3}$ & $\mathrm{~B}_{1}$ & 7 & $620 \pm 30$ \\
$0.02 \% \mathrm{Fe}-$ doped $\mathrm{LiNbO}_{3}$ & $\mathrm{~B}_{2}$ & 6 & $750 \pm 50$ \\
\hline
\end{tabular}

of $2 \%$. However, on the basis of the underlying assumptions behind the method of analysis, a larger uncertainty of $5 \%$ in the $\left(H_{\mathrm{v}}^{0}\right)$ values of the two $\mathrm{LiNbO}_{3}$ crystals is allowed. But, a still larger uncertainty of $7 \%$ is allowed for $\mathrm{Fe}$-doped $\mathrm{LiNbO}_{3}$, since the measurements were limited to a load of $100 \mathrm{~g}$, and also since the flat region of the $P-H_{\mathrm{v}}$ plot could not be reached.

The type of two-regime $P-H_{\mathrm{v}}$ plot, i.e. $H_{\mathrm{v}}$ increasing up to some load and then decreasing, observed by Dhanraj et al (1994), has not been observed in the present measurement. Instead, the $P-H_{\mathrm{v}}$ plots for all the three crystals are smooth monotonous curves showing the same trend viz. a large hardness value at low loads, followed by a steep fall with increasing loads, with a slower fall at still higher loads.

Based on measurements on two crystals of different origin, the true hardness value of $\mathrm{LiNbO}_{3}$ is estimated as $630 \pm 30 \mathrm{~kg} / \mathrm{mm}^{2}$ on the Vickers' scale and 5.6 on the Moh scale. The value of $570 \mathrm{~kg} / \mathrm{mm}^{2}$ obtained by Brown et al (1975) at $50 \mathrm{~g}$ load, and the value of $600 \mathrm{~kg} / \mathrm{mm}^{2}$ obtained by Dhanraj et al (1994) at $100 \mathrm{~g}$ load reconcile with the present value. The extreme values of 400 and $800 \mathrm{~kg} / \mathrm{mm}^{2}$ referred to in $\S 1$ appear to have resulted from some unidentified error. The $\mathrm{Fe}$-doped $\mathrm{LiNbO}_{3}$ has a larger hardness value of $750 \pm 50 \mathrm{~kg} / \mathrm{mm}^{2}$. The Fe impurity entering into the lattice impedes the movement of dislocations, thus enhancing the hardness. Such impurityenhanced hardness has been observed by other workers (Pratap and Hari Babu 1980).

It is to be noted that though the load vs hardness plots for crystals $\mathrm{A}$ and $\mathrm{B}_{1}$ nearly converge at high loads, there are large differences in the hardness values measured at low loads (note values of 865 and $1000 \mathrm{~kg} / \mathrm{mm}^{2}$ at $P=15 \mathrm{~g}$ for samples $\mathrm{A}$ and $\mathrm{B}_{1}$, (figure 2)). This reemphasizes the point made out by Thirmal Rao and Sirdeshmukh (1994) that hardness values of different crystals can be compared only when they have been evaluated from a systematic study of load variation.

\section{Conclusions}

Our studies on two samples of $\mathrm{LiNbO}_{3}$ of different origins have shown similar load variation of hardness. The load variation is smooth, and is consistent with the idea that the sample offers a deformation resistance pressure which reduces the applied load by a constant quantity. The true hardness value of $\mathrm{LiNbO}_{3}$, as determined, is 
$630 \pm 30 \mathrm{~kg} / \mathrm{mm}^{2}$. The microhardness value of Fe-doped $\mathrm{LiNbO}_{3}$, as determined, is $750 \pm \mathrm{kg} / \mathrm{mm}^{2}$.

\section{Acknowledgements}

The pure and doped $\mathrm{LiNbO}_{3}$ crystals were grown, oriented, cut and polished at the Solid State Physics Laboratory, Delhi, and were kindly gifted to the senior author (DBS) by the late Dr R Thyagarajan. Prof. H L Bhat, Indian Institute of Science, Bangalore, is thanked for sparing a clear polished sample of $\mathrm{LiNbO}_{3}$ and for useful discussions. The microhardness tester was acquired from a project grant to the senior author (DBS) by the UGC. DBS also thanks the UGC for support during this work in the form of an Emeritus Fellowship.

\section{References}

Chai B H T 1995 in CRC handbook of laser science and technology (Boca Raton: CRC Press) Suppl. 2
Brown H, Ballman A A and Chin G Y 1975 J. Mater. Sci. 10 1157

Dhanraj G, Bhat H L and Narayanan P S 1994 Ferroelectrics 1577

Hayes C and Kendall E G 1973 Metallography 6275

Mott B W 1956 Microindentation hardness testing (London: Butterworths)

Nikogosyan D N 1997 in Properties of optical and laser-related materials-A handbook (New York: John Wiley)

Pratap K J and Hari Babu V 1980 Bull. Mater. Sci. 243

Sangaiah G and Kishan Rao K 1993 Bull. Mater. Sci. 16397

Sirdeshmukh D B, Subhadra K G, Kishan Rao K and Thirmal Rao T 1995 Cryst. Res. Technol. 30861

Thirmal Rao T and Sirdeshmukh D B 1991 Cryst. Res. Technol. 26 K53

Thirmal Rao T and Sirdeshmukh D B 1994 Cryst. Res. Technol. 29 K112

Thyagarajan R 1989 in IV National seminar on crystal growth, Mysore

Upit G P and Varchenya S A 1973 in The science of hardness testing and its research applications (Metals Park, Ohio: American Society for Metals) 